\title{
Knowledge of Healthcare Workers Regarding Dengue and Chikungunya in Some Health Facilities of the City of Yaoundé (Cameroon) and Its Neighbourhood
}

\author{
Stella Mariette Nana-Ndjangwo',2, Ruth Mony', Roland Bamou'2,3, Gaël Bekono Ango' ${ }^{4}$, \\ Daina Paola Wantou Tchangou ${ }^{5}$, Parfait Awono-Ambene ${ }^{2}$, Charles Félix Bilong Bilong1, \\ Christophe Antonio-Nkondjio ${ }^{2,6^{*}}$
}

\author{
${ }^{1}$ Laboratory of Parasitology and Ecology, Faculty of Science, University of Yaoundé, Yaoundé, Cameroon \\ ${ }^{2}$ Institut de Recherche de Yaoundé (IRY), Organisation de Coordination pour la lutte Contre les Endémies en Afrique Centrale \\ (OCEAC), Yaoundé, Cameroon \\ ${ }^{3}$ Vector Borne Diseases Laboratory of the Applied Biology and Ecology Research Unit (VBID-URBEA), \\ Department of Animal Biology, Faculty of Science, University of Dschang, Dschang, Cameroon \\ ${ }^{4}$ Ecole des Sciences de la Santé, Université Catholique d'Afrique Centrale, Yaoundé, Cameroun \\ ${ }^{5}$ Institut Supérieur des Sciences et Techniques Appliquées à la Santé, Yaoundé, Cameroun \\ ${ }^{6}$ Vector Biology Liverpool School of Tropical Medicine Pembroke Place, Liverpool, UK \\ Email: stellanana123@gmail.com,ruthmony@yahoo.fr, bamou2011@gmail.com, bekonoangoo@gmail.com, \\ paolawan9@gmail.com,hpaawono@yahoo.fr, bilong_bilong@yahoo.com,*antonio_nk@yahoo.fr
}

How to cite this paper: Nana-Ndjangwo, S.M., Mony, R., Bamou, R., Ango'o, G.B., Tchangou, D.P.W., Awono-Ambene, P., Bilong, C.F.B. and Antonio-Nkondjio, C. (2021) Knowledge of Healthcare Workers Regarding Dengue and Chikungunya in Some Health Facilities of the City of Yaoundé (Cameroon) and Its Neighbourhood. Open Journal of Clinical Diagnostics, $11,77-91$.

https://doi.org/10.4236/ojcd.2021.113006

Received: May 25, 2021

Accepted: July 16, 2021

Published: July 19, 2021

Copyright $\odot 2021$ by author(s) and Scientific Research Publishing Inc. This work is licensed under the Creative Commons Attribution International License (CC BY 4.0).

http://creativecommons.org/licenses/by/4.0/

\begin{abstract}
Background: Good knowledge of diseases' epidemiology, diagnostic methods and treatment schemes are critical for early detection and effective management of dengue and chikungunya outbreaks. Here, we assessed knowledge and practices regarding dengue and chikungunya among health care workers of some health facilities of Yaoundé and its surroundings. Methods: A descriptive cross-sectional study was conducted from January to August 2020 in 35 health facilities of Yaoundé and its surroundings. Structured pre-tested questionnaire including 11 questions was used to assess healthcare workers' (i) knowledge on dengue and chikungunya (pathogen, mode of transmission, signs and symptoms) and, (ii) management practices (diagnosis, prevention and treatment measures). Face to face interviews were conducted with healthcare workers including medical doctors, nurses, medical assistants and laboratory assistants. Findings: A total of 232 healthcare workers were interviewed. Despite that $40.95 \%(n=95)$ of respondents had heard about dengue and chikungunya, only $4.74 \%(\mathrm{n}=11)$ of them were aware of the fact that both diseases are caused by virus. Also, 9 out of $232(3.88 \%)$ knew that these
\end{abstract}


diseases were transmitted by the bite of an Aedes mosquito. About 15.52\% (n $=36$ ) were able to give at least 1 clinical symptom related to dengue and chikungunya. The main diagnostic method they knew was Polymerase Chain Reaction $(3.02 \% ; n=7)$. For prevention, many participants indicated vector control by using insecticide treated bednets or destroying potential breeding sites $(14.23 \% ; n=33)$. Only few participants $3.88 \%(n=9)$ knew how to manage dengue or chikungunya cases. To improve the management of both diseases, a significant proportion of healthcare workers $(37.93 \% ; n=88)$ reported being in need of additional training. Conclusion: The poor knowledge regarding dengue and chikungunya among healthcare workers in Yaoundé and its neighbourhood raises the need to intensify sensitization campaigns and training activities towards this personnel.

\section{Keywords}

Dengue, Chikungunya, Healthcare Workers Knowledge, Management Practices

\section{Introduction}

Dengue and chikungunya are both arthropod-borne viral (arboviral) diseases originating from Africa. Over the last 50 years, the public health impact of both diseases has dramatically escalated across the world [1] [2]. The spread of these diseases could have resulted from extensive migration and trade from Africa to the rest of the world [3] [4]. Nowadays, these diseases are maintained in endemic or epidemic cycles and vectored by mosquitoes of the Aedes genus with Aedes aegypti and Aedes albopictus as the main vector species [6] [7]. For chikungunya (Togaviridae, Alphavirus genus) it is estimated that 1.3 billion people in 94 countries are exposed to the risk of transmission of this disease [7]. Dengue virus (Flaviviridae, Flavivirus genus) causes the most common arboviral disease and over 3.9 billion people in 129 countries live at risk of the disease [8] [9]. Dengue and chikungunya display similar clinical symptoms such as fever, headache, arthralgia, myalgia and rash [10] [11]. Due to the similarity of these symptoms to those of malaria, clinicians usually overlook the possibility that a different infection could be found in febrile patients, especially in malaria endemic countries. This situation leads to overdiagnosis of malaria including prescription of antimalarial drugs to patients without evidence of malaria parasitaemia and frequent absence of treatment for alternative causes of disease [12] [13] [14].

Dengue and chikungunya cases have been frequently reported in Cameroon since 2000s [15] [16]. Even though the country has so far not registered major outbreaks, cases of dengue have been reported across the country with prevalence of $\operatorname{IgG}$ in the population varying from $9.8 \%$ in the city of Yaoundé to $61.4 \%$ in the city of Douala [17]. Chikungunya is also highly prevalent across the country with several cases reported in different epidemiological settings [18] [19] [20]. Because there is no available vaccines for these diseases, successful 
control relies on the education/sensitization of communities, prevention of mosquito breeding and bites and good management of cases by healthcare workers [21] [22]. This supposes that care givers should have good knowledge and should be well trained to deliver good diagnosis and better treatment to people affected by dengue and chikungunya. Despite the rapid expansion of both diseases in Cameroon, there have been so far not enough programs incorporating sociological approaches to understand and design interventions aiming at preventing and controlling these diseases in infection prone area. Therefore, the present study uses a socio-ecological approach to assess the knowledge and practices regarding dengue and chikungunya among healthcare workers in different healthcare facilities in the city of Yaoundé and its neighbourhood. This study highlights areas that need to be addressed through training and health promotion activities to enhance case management and the control of dengue and chikungunya in Cameroon.

\section{Methods}

\section{Study Sites}

This survey was conducted in some health facilities of the city of Yaoundé and its surroundings, from January to August 2020. Yaoundé, the political capital of Cameroon, is one of the most populated cities of the country and thus includes a high number of healthcare facilities and workers whose distribution is heterogeneous with areas of high densities such as the urban centres and low densities at the city periphery [23] [24].

\section{Study design}

This study is a descriptive cross-sectional survey, conducted to assess health care workers' (HCWs) knowledge and practices concerning prevention, diagnostic and case management of dengue and chikungunya. Face to face interviews were conducted following non-probability convenience sampling. A total of 35 private and public healthcare facilities, distributed across 8 health districts of Yaoundé and its neighbourhood were randomly selected for this study. Managers of the different health facilities were informed about the study in order to obtain their consent; then the healthcare workers were asked to voluntarily participate in the study. In each health facility the following health personnel were enrolled for the study on a voluntary basis (medical doctors, nurses, laboratory technicians, medical assistants). A questionnaire consisting of 11 opened ended and true/false questions was prepared after non-exhaustive literature review. The questionnaire was structured into 3 parts: 1) identification of the participant; 2) general knowledge; and 3) case management (diagnosis, prevention and treatment measures) of dengue and chikungunya (see supplementary file). Demographic variables recorded were health district, sex and profession. After sampling tool preparation, internal reviews were done by peers and senior researchers to assess questions clarity. After peers' reviews, a pre-test on 30 students, from the Faculty of Medicine and Biomedical Science of the University of 
Yaoundé 1 and from the Catholic University of Central Africa, was undertaken to test for questionnaire's validity, internal consistency and reliability. One week after the first test a second test was done on the same cohort and the number of good answers was recorded in order to measure test-retest reliability. All participants responded without any difficulty to all questions. Over $90 \%$ of participants in the second round (retest) responded similarly to the questions as they did in the first test. Participants were not informed of the second test. The validity of the test was ascertained by the laboratory supervisor.

Before the beginning of the survey, interviewers were trained on how to use the questionnaire and on methods to approach respondents and obtain consent. In each health facility, questionnaires were administered either in French or English. The number of people interviewed per hospital varied on willingness to take part to the study.

\section{Ethical approval and concern to participate}

This study received the ethical clearance No 2657/CRERSHC/2020 delivered by the Centre Regional Ethics Committee for Human Health Research. Further consent to participate was obtained from each head of health facility and respondents after explaining the study objectives.

\section{Data analysis}

Data collected were registered into a Microsoft Excel database. All completed questionnaires were double checked and verified for completeness and consistency. Was considered as outcome variables knowledge and practices while independent variables were age, gender and profession. Descriptive analysis was performed on qualitative data presented in frequencies and a chi square test was used to compare knowledge between professions.

To assess knowledge related to dengue and chikungunya, HCWs were asked about 4 questions concerning: pathogen, mode of transmission, symptoms and diagnostic practices. Respondents who correctly answered to at least 3 out of 4 questions were considered as having a "good knowledge" of dengue and chikungunya while those who correctly answered to two or less were considered as having "poor knowledge". Statistical analyses were undertaken with $\mathrm{R}$ version 3.6.3 [25], at significance level of $\alpha=0.05$. A binary logistic regression model was computed using generalized linear model (glm) function and compiling the forestmodel to assess relationship between profession and knowledge of dengue and chikungunya. Odds ratios and their $95 \%$ confidence intervals were estimated.

\section{Results}

\section{Characteristics of the sampled population}

The questionnaire was submitted to 232 healthcare personnel working in 35 health care facilities, i.e. 119 from 11 public health facilities and 113 from 24 private health facilities (Table 1). Among the 232 interviewed participants, $73.7 \%$ were female $(n=171)$ and $26.3 \%$ were male $(n=61)$. The sample included 
Table 1. Characteristics of healthcare workers surveyed in some health districts in Yaoundé and its neighbourhood.

\begin{tabular}{cccc}
\hline Variables & Modalities & $\mathbf{n}$ & Frequency (\%) \\
\hline \multirow{2}{*}{ Type of health facility } & Public & 119 & 51.3 \\
& Private & 113 & 48.7 \\
\hline \multirow{2}{*}{ Gender } & Female & 171 & 73.7 \\
& Male & 61 & 26.3 \\
\hline \multirow{2}{*}{ Profession } & Medical assistant & 63 & 27.15 \\
& Medical doctor & 44 & 18.97 \\
& Nurse & 79 & 34.05 \\
& Technician & 46 & 19.83
\end{tabular}

n: number of personnel interviewed.

nurses $(34.05 \% ; \mathrm{n}=79)$, medical assistants $(27.15 \% ; \mathrm{n}=63)$, laboratory technicians $(19.83 \% ; \mathrm{n}=46)$ and medical doctors $(18.97 \% ; \mathrm{n}=44)$ (Table 1$)$.

General knowledge of studied population regarding dengue and chikungunya

Only 95 (40.95\%) out of 232 participants interviewed had heard about dengue and chikungunya. The awareness rate of the diseases significantly varied with profession $\left(\chi^{2}=42.12 ; P<0.001\right)$ : $70.45 \%$ (31/44) for medical doctors, $9.52 \%$ $(6 / 63)$ for medical assistants, $39.24 \%$ (31/79) for nurses and $58.7 \%(27 / 46)$ for lab technicians (Table 2).

When respondents were asked how they first learned about these diseases, $12.07 \%(\mathrm{n}=28)$ said it was when attending to school classes. Other answers provided were personal research through reading $(3.45 \% ; \mathrm{n}=8)$; media during outbreaks around the world $(3.02 \% ; \mathrm{n}=7)$; health statistics sheets provided by the Ministry of Health $(2.59 \% ; \mathrm{n}=6)$ and discussions with mates $(1.29 \% ; \mathrm{n}=3)$. Varying responses were provided according to the profession (Table 2). It appeared that $77.15 \%$ (179/232) of the personnel and more than $60 \%$ in each profession did not know about these diseases.

Concerning knowledge on the pathogen, just $4.74 \%(\mathrm{n}=11)$ of the HCWs knew that both diseases are caused by virus (8/44 medical doctors and 3/46 lab technicians). Many have confused the vector to the pathogen giving answers such as Plasmodium species, Aedes, Culex, bats, dogs, insects and mosquitoes with a great proportion of respondents ignoring the answer (Table 2). No medical assistant or nurse knew about the pathogens.

Among the 232 interviewed HCWs, 38 (16.38\%) knew that these diseases are transmitted by mosquitoes' bites. Precisely, only 9 personnel (3.88\%) including 5 medical doctors, 2 nurses and 2 lab technicians indicated that these arboviral infections are transmitted through Aedes mosquito bites (Table 2).

When participants were asked about the diseases symptoms, no medical assistant could give any symptom of the diseases. Furthermore, the majority of 
Table 2. Dengue and chikungunya knowledge of healthcare workers in some health care facilities of the city of Yaoundé and its neighbourhood.

\begin{tabular}{|c|c|c|c|c|c|c|c|c|c|c|}
\hline \multirow{3}{*}{ Questions/Answers } & \multicolumn{8}{|c|}{ Profession } & \multirow[b]{3}{*}{ Total } & \multirow[b]{3}{*}{$\%$} \\
\hline & \multicolumn{2}{|c|}{ Medical doctor } & \multicolumn{2}{|c|}{ Medical assistant } & \multicolumn{2}{|c|}{ Nurse } & \multicolumn{2}{|c|}{ Lab technician } & & \\
\hline & $\mathbf{n}$ & $\%$ & $\mathbf{n}$ & $\%$ & $\mathbf{n}$ & $\%$ & $\mathbf{n}$ & $\%$ & & \\
\hline \multicolumn{11}{|l|}{ Have you ever heard about these diseases? } \\
\hline Yes & 31 & 70.45 & 6 & 9.52 & 31 & 39.24 & 27 & 58.7 & 95 & 40.95 \\
\hline No & 13 & 29.55 & 57 & 90.48 & 48 & 60.76 & 19 & 41.3 & 137 & 59.05 \\
\hline Total & 44 & 100 & 63 & 100 & 79 & 100 & 46 & 100 & 232 & 100 \\
\hline \multicolumn{11}{|l|}{ How did you heard of these diseases? } \\
\hline Confirmed case & 1 & 2.27 & 0 & 0 & 0 & 0 & 0 & 0 & 1 & 0.43 \\
\hline Discussions & 0 & 0 & 1 & 1.59 & 2 & 2.53 & 0 & 0 & 3 & 1.29 \\
\hline Health statistics & 0 & 0 & 1 & 1.59 & 4 & 5.06 & 1 & 2.17 & 6 & 2.59 \\
\hline Media & 2 & 4.55 & 0 & 0 & 3 & 3.8 & 2 & 4.35 & 7 & 3.02 \\
\hline Personal research & 3 & 6.82 & 0 & 0 & 3 & 3.8 & 2 & 4.35 & 8 & 3.45 \\
\hline School & 11 & 25 & 1 & 1.59 & 9 & 11.39 & 7 & 15.22 & 28 & 12.07 \\
\hline Don't know & 27 & 61.36 & 60 & 95.23 & 58 & 73.42 & 34 & 73.91 & 179 & 77.15 \\
\hline Total & 44 & 100 & 63 & 100 & 79 & 100 & 46 & 100 & 232 & 100 \\
\hline \multicolumn{11}{|l|}{ What is the pathogen? } \\
\hline Virus & 8 & 18.18 & 0 & 0 & 0 & 0 & 3 & 6.52 & 11 & 4.74 \\
\hline $\begin{array}{l}\text { Wrong answers (Plasmodium sp., Aedes, Culex, } \\
\text { bats, dogs, insects, mosquitoes, don't know) }\end{array}$ & 36 & 81.82 & 63 & 100 & 79 & 100 & 43 & 93.88 & 221 & 95.26 \\
\hline Total & 44 & 100 & 63 & 100 & 79 & 100 & 46 & 100 & 232 & 100 \\
\hline \multicolumn{11}{|l|}{ How are they transmitted to human? } \\
\hline Aedes or mosquito bites & 16 & 36.36 & 1 & 1.59 & 10 & 12.66 & 11 & 23.91 & 38 & 16.38 \\
\hline Wrong answers (flies or tick bites, raw meat, don't know) & 28 & 63.64 & 62 & 98.41 & 69 & 87.34 & 35 & 76.09 & 194 & 83.62 \\
\hline Total & 44 & 100 & 63 & 100 & 79 & 100 & 46 & 100 & 232 & 100 \\
\hline \multicolumn{11}{|l|}{ What are these diseases symptoms? } \\
\hline Joint pain & 11 & 25 & 0 & 0 & 1 & 1.27 & 2 & 4.35 & 14 & 6.04 \\
\hline Muscle pain & 3 & 6.82 & 0 & 0 & 0 & 0 & 1 & 2.17 & 4 & 1.72 \\
\hline Bleeding & 7 & 15.9 & 0 & 0 & 0 & 0 & 0 & 0 & 7 & 3.02 \\
\hline Rash & 3 & 6.82 & 0 & 0 & 2 & 2.53 & 0 & 0 & 5 & 2.15 \\
\hline Vomiting & 3 & 6.82 & 0 & 0 & 2 & 2.53 & 0 & 0 & 5 & 2.15 \\
\hline Retro-orbital pain & 0 & 0 & 0 & 0 & 1 & 1.27 & 0 & 0 & 1 & 0.43 \\
\hline Don’t know & 17 & 38.64 & 63 & 100 & 73 & 92.4 & 43 & 93.48 & 196 & 84.48 \\
\hline Total & 44 & 100 & 63 & 100 & 79 & 100 & 46 & 100 & 232 & 100 \\
\hline \multicolumn{11}{|l|}{ What are the most affected populations? } \\
\hline Tropical, forest and rural populations & 4 & 9.09 & 0 & 0 & 2 & 2.53 & 5 & 10.87 & 11 & 4.74 \\
\hline Wrong answers (eldery, children, pregnant woman, don't know) & 40 & 90.9 & 63 & 100 & 77 & 97.47 & 41 & 89.13 & 221 & 95.26 \\
\hline Total & 44 & 29.54 & 63 & 100 & 79 & 100 & 46 & 100 & 232 & 100 \\
\hline
\end{tabular}


participants $(84.48 \% ; n=196)$ could not cite any symptom. Symptoms reported by participants aware of the diseases included joint pain $(6.04 \% ; n=14)$; muscle pain $(1.72 \% ; \mathrm{n}=4)$; bleeding $(3.02 \% ; \mathrm{n}=7)$; rash $(2.15 \% ; \mathrm{n}=5)$; persistent vomiting $(2.15 \% ; n=5)$ and retro-orbital pain $(0.43 \% ; n=1)$ (Table 2$)$.

Concerning people at risk, $4.74 \%(\mathrm{n}=11)$ of the participants answered that the most affected are those living in the tropical, forest zone or in rural areas while many $95.26 \%(n=221)$ gave wrong or no answers (Table 2).

Relationship between profession and knowledge of dengue and chikungunya

A binary logistic regression was conducted to assess the correlation between knowledge and profession (Figure 1). From this analysis, a significant difference appeared between medical doctors versus medical assistants (OR: 89.56, 95\% CI: 17.20 - 1654.10, $P<0.001$ ), technicians versus medical assistants (OR: 36.34, 95\% CI: $6.95-670.68, P<0.001)$ and nurses versus medical assistants (OR: 14.53, 95\% CI: $2.81-266.71, P<0.001)$.

Knowledge of diagnostic, prevention and treatment practices of HCWs for dengue and chikungunya

Of all interviewed HCWs, only 11 (4.74\%) were able to cite methods used for the diagnosis of dengue and chikungunya. Techniques cited by those who correctly answered to this question included PCR $(3.02 \% ; n=7)$, serology $(0.43 \%, n$ $=1$ ) and RDTs $(1.29 \%, \mathrm{n}=3)$. Some participants also cited thick blood smear or scanner $(3.45 \%, \mathrm{n}=8)$. No medical assistant was able to give any correct diagnostic method for dengue and chikungunya (Table 3 ).

Concerning prevention, some HCWs indicated vaccination $(0.86 \% ; n=2)$, while many of them indicated the use of vector control measures such as destruction of mosquito potential breeding sites, sleeping under treated nets or using repellents $(14.23 \%, \mathrm{n}=33$ ) (Table 3 ).

The majority of participants could not provide any answer regarding the treatment of these diseases. Few of them $(4.31 \%, \mathrm{n}=10)$ and mainly medical doctors $(15.91 \% ; n=7)$ reported that both diseases treatment relies on symptoms relief (Table 3 ).

\begin{tabular}{|c|c|c|c|c|}
\hline Profession & $\mathbf{n}$ & Odds ratio & Odds ratio (Cl) & $\mathbf{p}$ \\
\hline medical_assistant & 63 & i & Reference & \\
\hline medical_doctor & 44 & - & $89.56(17.20,1654.10)$ & $<0.001$ \\
\hline nurse & 79 & 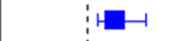 & $14.53(2.81,266.71)$ & 0.01 \\
\hline technician & 46 & ㄴ & $36.34(6.95,670.68)$ & $<0.001$ \\
\hline (Intercept) & & $\mapsto$ & $0.02(0.00,0.07)$ & $<0.001$ \\
\hline
\end{tabular}

Figure 1. Results of binary logistic regression comparing the knowledge of different categories of HCW on dengue and chikungunya. 


\section{Good knowledge and good practices}

From this work, only $3.02 \%$ of interviewed HCWs ( $n=7$ including 6 medical doctors and 1 laboratory technician) were identified as having "good knowledge" of dengue and chikungunya.

\section{Improvement propositions}

When HCWs were asked if they were well trained to handle dengue and chikungunya cases, most of them $(96.12 \%, \mathrm{n}=223)$ answered negatively (Table 4).

Table 3. Diagnosis, prevention and treatment practices related to dengue and chikungunya among HCWs of some health care facilities of the city of Yaoundé and its surroundings.

\begin{tabular}{|c|c|c|c|c|c|c|c|c|c|c|}
\hline \multirow{3}{*}{ Variables } & \multicolumn{8}{|c|}{ Profession } & \multirow[b]{3}{*}{ Total } & \multirow[b]{3}{*}{$\%$} \\
\hline & \multicolumn{2}{|c|}{ Medical doctor } & \multicolumn{2}{|c|}{ Medical assistant } & \multicolumn{2}{|c|}{ Nurse } & \multicolumn{2}{|c|}{ Lab technician } & & \\
\hline & $\mathrm{n}$ & $\%$ & $\mathrm{n}$ & $\%$ & $\mathbf{n}$ & $\%$ & $\mathrm{n}$ & $\%$ & & \\
\hline \multicolumn{11}{|l|}{ Diagnostic methods } \\
\hline PCR & 4 & 9.09 & 0 & 0 & 1 & 1.27 & 2 & 4.35 & 7 & 3.02 \\
\hline Serology & 1 & 2.27 & 0 & 0 & 0 & 0 & 0 & 0 & 1 & 0.43 \\
\hline Rapid Diagnostic Test & 0 & 0 & 0 & 0 & 1 & 1.27 & 2 & 4.35 & 3 & 1.29 \\
\hline $\begin{array}{l}\text { Wrong answers (thick blood smear, scanner, } \\
\text { psychiatric examination, don't know) }\end{array}$ & 39 & 88.64 & 63 & 100 & 77 & 97.46 & 42 & 91.3 & 221 & 95.26 \\
\hline Total & 44 & 100 & 63 & 100 & 79 & 100 & 46 & 100 & 232 & 100 \\
\hline \multicolumn{11}{|l|}{ Preventive Measures } \\
\hline Vector control & 12 & 27.27 & 2 & 3.17 & 5 & 6.33 & 14 & 30.43 & 33 & 14.23 \\
\hline Vaccination & 0 & 0 & 1 & 1.59 & 0 & 0 & 1 & 2.17 & 2 & 0.86 \\
\hline $\begin{array}{l}\text { Wrong answers (eat properly cooked meat, } \\
\text { handwashing, avoid wild animals, don't know) }\end{array}$ & 32 & 72.73 & 60 & 95.24 & 74 & 93.67 & 31 & 67.4 & 197 & 84.91 \\
\hline Total & 44 & 100 & 63 & 100 & 79 & 100 & 46 & 100 & 232 & 100 \\
\hline \multicolumn{11}{|l|}{ Case management } \\
\hline Symptomatic & 7 & 15.91 & 0 & 0 & 3 & 3.8 & 0 & 0 & 10 & 4.31 \\
\hline $\begin{array}{l}\text { Wrong answers (traditional treatment, } \\
\text { psychiatric management, don't know) }\end{array}$ & 37 & 84.09 & 63 & 100 & 76 & 96.2 & 46 & 100 & 222 & 95.69 \\
\hline Total & 44 & 100 & 63 & 100 & 79 & 100 & 46 & 100 & 232 & 100 \\
\hline
\end{tabular}

Table 4. Propositions for the improvement of case management of dengue and chikungunya.

\begin{tabular}{ccc}
\hline Variables & n & Frequency (\%) \\
\hline Medical staff properly trained for cases management & & \\
Yes & 9 & 3.88 \\
No & 223 & 96.12 \\
Improve dengue/chikungunya management in clinic & & \\
Train medical staff & 88 & 37.93 \\
Informing the population & 23 & 9.91 \\
Increase sensitization activities & 15 & 6.47 \\
No idea & 106 & 45.69 \\
\hline
\end{tabular}


To improve case management of both diseases, $72.73 \%(\mathrm{n}=88)$ of participants suggested that medical staff should be properly trained; some $(9.91 \%, \mathrm{n}=$ 23) indicated that populations should be sensitize on these diseases. Some HCWs $(6.47 \% ; n=15)$ proposed to increase sensitization over media and that large scale seroprevalence survey should also be undertaken. A large number of HCWs (45.69\%; $\mathrm{n}=106)$ did not had any idea on how to improve these diseases management (Table 4).

\section{Discussion}

The study main objective was to assess knowledge and practices of HCWs from the city of Yaoundé and its neighbourhood on dengue and chikungunya (knowledge of pathogens, mode of transmission, case management and preventive measures) in order to identify knowledge gaps that could be targeted to improve healthcare workers ability to detect and manage properly dengue and chikungunya cases.

Poor knowledge and poor practices of health personnel concerning these diseases were recorded. Less than $41 \%$ of interviewed participants heard about both diseases. A similar assessment in Tanzania indicated that $96.8 \%$ of respondents knew about dengue, whereas $87.2 \%$ have never heard of chikungunya [14]. Good knowledge of mosquito vector and signs and symptoms of dengue and chikungunya cases are key for identifying the disease and seeking for appropriate medical treatment to save lives [26] [27]. In Cameroon, the low awareness of the medical personnel about these diseases could derive from the perceived low transmission risk and low endemicity of these diseases. Serological surveys conducted in the population indicated prevalence of $9.8 \%$ and $14.4 \%$ for dengue IgG and IgM respectively [17] [28]. However, sporadic cases and outbreaks of chikungunya are frequent in the country [18] [19] [20] and support high and frequent circulation of these pathogens. Chikungunya, dengue and malaria have similar symptoms that are difficult to differentiate clinically [29]. The hyperendemicity of malaria in Cameroon could have limited the capacity of the health personnel to also screen for the presence of other diseases. In most African health care centres diagnostic tests for diseases such as dengue and chikungunya are unavailable. It is also not common to find medical doctors prescribing diagnosis of dengue and chikungunya to patients with fever like symptoms [13]. This could have all limited the knowledge and awareness of HCWs about these diseases.

Medical doctors appeared as the group most aware of dengue and chikungunya compared to other personnel. They were the most represented group among respondents with good knowledge of the diseases $(n=6$ out of 7 ), whereas laboratory technicians were minimally represented $(n=1)$. The poor knowledge of medical assistants and nurses may be due to the fact that their training programs give more emphasis on case management of common diseases in the country. It could also be due to the fact that in their duty, this personnel in urban settings is not directly involved in consultations or examinations of pa- 
tients, but mainly provide care to patients [30] [31]. The fact that these groups constitute the first line of health personnel called upon during emergencies or diseases outbreaks highlights the need for adequate training for them. A significant proportion of respondents (39.93\%) reported being in need of specific training programs on neglected diseases and new diagnostic techniques which are not always offered in hospitals. Rapid diagnostic tests for dengue and chikungunya were found not to be used in routine in hospitals; these tools could be an alternative to the poor equipment of most health care facilities [32]. Capacity strengthening of the health personnel on the epidemiology, particularly the aetiology, mode of transmission, diagnosis and case management is key for the proper handling of cases. This could be achieved through different approaches such as train-the-trainer approach with grand-rounds style presentations which proved to be effective for physicians involved with dengue management in Florida [33]. Another approach is to integrate dengue and chikungunya in health education programmes using posters and video exhibition related to both diseases [34]. Since these diseases have similar symptoms with malaria, clear definition of a standard case need to be provided [35] [36] [37]. Regular sensitization campaigns also need to be conducted to improve knowledge of HCWs and community members on how to prevent and treat dengue and chikungunya. Clinicians should also be encouraged to read more and to improve their knowledge on diseases or diagnostic tools and regular evaluation of this personnel should be undertaken to make sure that they are up to the task and well fit to address challenges.

The present study had the following limitations. It did not recorded the number years of seniority in the post or working experience of HCWs to assess whether the poor knowledge was associated to the lack of experience. Also other sampling methods such as focus group discussions or in-depth interviews were not conducted to further probe into the knowledge and practices of the medical personnel. The study had a small sample size and targeted HCWs. There is a need for geographical wide representative survey to assess knowledge and practices of both the medical personnel and the general population.

\section{Conclusion}

This study has revealed poor knowledge of healthcare workers regarding dengue and chikungunya in health care facilities of Yaoundé and its neighbourhood, highlighting significant gaps in the diagnosis of both diseases. Regular sensitization campaigns on these diseases through the media and specific training activities have to be implemented to improve HCWs capacity to diagnose and manage dengue and chikungunya cases. Further similar surveys on HCWs across the country also need to be conducted to have a better appraisal of this personnel knowledge and skill gaps on different endemic diseases which are so far neglected and which yearly results in deaths which could have been avoided if the personnel was well trained. 


\section{Funding}

This study was funded by the Control of NTDs in Central Africa project implemented by "Organisation de Coordination pour la lutte contre les Endémies en Afrique Centrale" (OCEAC), and funded by the German Federal Ministry for Economic Cooperation and Development (BMZ) through the German Development Bank (KfW) awarded to SMN-N. The funding body did not have any role in the design, collection of data, analysis and interpretation of data and in writing of the manuscript.

\section{Author Contributions}

SMN-N, RM and CAN conceptualized and designed the study; SMN-N, RB, GBA, DPWT and CAN participated in data collection; SMN-N and CAN performed statistical analysis and wrote the manuscript; RB, GBA, DPWT, PAA and CFBB critically reviewed and amended the manuscript. All the authors read and approved the final manuscript.

\section{Acknowledgements}

The authors would like to thank all the participants and the managers of each health facility for their collaboration.

\section{Conflicts of Interest}

The authors declare no conflicts of interest regarding the publication of this paper.

\section{References}

[1] Furuya-Kanamori, L., Liang, S., Milinovich, G., Soares Magalhaes, R.J., Clements, A.C.A., Hu, W., et al. (2016) Co-Distribution and Co-Infection of Chikungunya and Dengue Viruses. BMC Infectious Diseases, 16, 84. https://doi.org/10.1186/s12879-016-1417-2

[2] Weaver, S.C. (2014) Arrival of Chikungunya Virus in the New World: Prospects for Spread and Impact on Public Health. PLOS Neglected Tropical Diseases, 8, e2921. https://doi.org/10.1371/journal.pntd.0002921

[3] Braack, L., Gouveia de Almeida, A.P., Cornel, A.J., Swanepoel, R. and de Jager, C. (2018) Mosquito-Borne Arboviruses of African Origin: Review of Key Viruses and Vectors. Parasites \& Vectors, 11, 29. https://doi.org/10.1186/s13071-017-2559-9

[4] Liang, G., Gao, X. and Gould, E.A. (2015) Factors Responsible for the Emergence of Arboviruses; Strategies, Challenges and Limitations for Their Control. Emerging Microbes \& Infections, 4, 1-5. https://doi.org/10.1038/emi.2015.18

[5] Delatte, H., Bagny, L., Brengue, C., Bouetard, A., Paupy, C. and Fontenille, D. (2011) The Invaders: Phylogeography of Dengue and Chikungunya Viruses Aedes Vectors, on the South West Islands of the Indian Ocean. Infection, Genetics and Evolution, 11, 1769-1781. https://doi.org/10.1016/j.meegid.2011.07.016

[6] Kraemer, M.U., Sinka, M.E., Duda, K.A., Mylne, A.Q., Shearer, F.M., Barker, C.M., et al. (2015) The Global Distribution of the Arbovirus Vectors Aedes aegypti and Ae. albopictus. eLife, 4, e08347. https://doi.org/10.7554/eLife.08347 
[7] Nsoesie, E.O., Kraemer, M.U., Golding, N., Pigott, D.M., Brady, O.J., Moyes, C.L., et al. (2016) Global Distribution and Environmental Suitability for Chikungunya Virus, 1952 to 2015. Eurosurveillance, 21, 30234. https://doi.org/10.2807/1560-7917.ES.2016.21.20.30234

[8] Bhatt, S., Gething, P.W., Brady, O.J., Messina, J.P., Farlow, A.W., Moyes, C.L., et al. (2013) The Global Distribution and Burden of Dengue. Nature, 496, 504-507. https://doi.org/10.1038/nature12060

[9] Brady, O. (2019) Mapping the Emerging Burden of Dengue. eLife, 8, e47458. https://doi.org/10.7554/eLife.47458

[10] Pialoux, G., Gaüzère, B.-A., Jauréguiberry, S. and Strobel, M. (2007) Chikungunya, an Epidemic Arbovirosis. The Lancet Infectious Diseases, 7, 319-327. https://doi.org/10.1016/S1473-3099(07)70107-X

[11] Staples, J.E., Breiman, R.F. and Powers, A.M. (2009) Chikungunya Fever: An Epidemiological Review of a Re-Emerging Infectious Disease. Clinical Infectious Diseases, 49, 942-948. https://doi.org/10.1086/605496

[12] Chandler, C.I.R., Mangham, L., Njei, A.N., Achonduh, O., Mbacham, W.F. and Wiseman, V. (2012) "As a Clinician, You Are Not Managing Lab Results, You Are Managing the Patient": How the Enactment of Malaria at Health Facilities in Cameroon Compares with New WHO Guidelines for the Use of Malaria Tests. Social Science \& Medicine, 74, 1528-1535. https://doi.org/10.1016/j.socscimed.2012.01.025

[13] Chipwaza, B., Mugasa, J.P., Mayumana, I., Amuri, M., Makungu, C. and Gwakisa, P.S. (2014) Community Knowledge and Attitudes and Health Workers' Practices Regarding Non-Malaria Febrile Illnesses in Eastern Tanzania. PLOS Neglected Tropical Diseases, 8, e2896. https://doi.org/10.1371/journal.pntd.0002896

[14] Kajeguka, D.C., Desrochers, R.E., Mwangi, R., Mgabo, M.R., Alifrangis, M., Kavishe, R.A., et al. (2017) Knowledge and Practice Regarding Dengue and Chikungunya: A Cross-Sectional Study among Healthcare Workers and Community in Northern Tanzania. Tropical Medicine \& International Health, 22, 583-593. https://doi.org/10.1111/tmi.12863

[15] Krippner, R. and Laer, G. (2002) First Confirmed Dengue-1 Fever Cases Reported from Cameroon. Journal of Travel Medicine, 9, 273-274.

https://doi.org/10.2310/7060.2002.24119

[16] Peyrefitte, C.N., Rousset, D., Pastorino, B.A.M., Pouillot, R., Bessaud, M., Tock, F., et al. (2007) Chikungunya Virus, Cameroon, 2006. Emerging Infectious Diseases, 13, 768. https://doi.org/10.3201/eid1305.061500

[17] Demanou, M., Pouillot, R., Grandadam, M., Boisier, P., Kamgang, B., Hervé, J.P., et al. (2014) Evidence of Dengue Virus Transmission and Factors Associated with the Presence of Anti-Dengue Virus Antibodies in Humans in Three Major Towns in Cameroon. PLOS Neglected Tropical Diseases, 8, e2950.

https://doi.org/10.1371/journal.pntd.0002950

[18] Demanou, M., Antonio-Nkondjio, C., Ngapana, E., Rousset, D., Paupy, C., Manuguerra, J.-C., et al. (2010) Chikungunya Outbreak in a Rural Area of Western Cameroon in 2006: A Retrospective Serological and Entomological Survey. BMC Research Notes, 3, 128. https://doi.org/10.1186/1756-0500-3-128

[19] Demanou, M., Alain, S.-M.S., Christophe, V., Rene, N., Irene, K.T., Marthe, I.N., et al. (2015) Molecular Characterization of Chikungunya Virus from Three Regions of Cameroon. Virologica Sinica, 30, 470-473. https://doi.org/10.1007/s12250-015-3663-7

[20] Fokam, E.B., Levai, L.D., Guzman, H., Amelia, P.A., Titanji, V.P.K., Tesh, R.B., et al. 
(2010) Silent Circulation of Arboviruses in Cameroon. East African Medical Journal, 87, 262-268. https://doi.org/10.4314/eamj.v87i6.63085

[21] Simon, F., Javelle, E., Cabié, A., Bouquillard, E., Troisgros, O., Gaétan, G., et al. (2015) French Guidelines for the Management of Chikungunya (Acute and Persistent Presentations) November 2014. Médecine et Maladies Infectieuses, 45, 243-263. https://doi.org/10.1016/j.medmal.2015.05.007

[22] WHO (2018) Managing Epidemics: Key Facts about Major Deadly Diseases. World Health Organization, Geneva.

[23] BUCREP (2010) Troisième recensement générale de la population et de l'habitat. Third General Population and Housing Census Cameroun. Rapport de présentation des résulstats définitifs République du Cameroun. 1-65.

[24] Geomatic Strategy (2019) Stratégies Spatiales n² (Mars-Avril 2019): Analyse géographique de la couverture sanitaire au Cameroun; Répartition des formations sanitaires et de la charge du personnel de santé.

[25] R Core Team (2018) R: A Language and Environment for Statistical Computing. R Foundation for Statistical Computing, Vienna.

[26] WHO (2012) Global Strategy for Dengue Prevention and Control 2012-2020.

[27] Yboa, B.C. and Labrague, L.J. (2013) Dengue Knowledge and Preventive Practices among Rural Residents in Samar Province, Philippines. American Journal of Public Health, 1, 47-52. https://doi.org/10.12691/ajphr-1-2-2

[28] Tchuandom, S.B., Tchouangueu, T.F., Antonio-Nkondjio, C., Lissom, A., Djang, J.O.N., Atabonkeng, E.P., et al. (2018) Seroprevalence of Dengue Virus among Children Presenting with Febrile Illness in Some Public Health Facilities in Cameroon. The Pan African Medical Journal, 31, 177. https://doi.org/10.11604/pamj.2018.31.177.16390

[29] Mardekian, S.K. and Roberts, A.L. (2015) Diagnostic Options and Challenges for Dengue and Chikungunya Viruses. BioMed Research International, 2015, e834371. https://doi.org/10.1155/2015/834371

[30] Bodenheimer, T., Willard-Grace, R. and Ghorob, A. (2014) Expanding the Roles of Medical Assistants: Who Does What in Primary Care? JAMA Internal Medicine, 174, 1025-1026. https://doi.org/10.1001/jamainternmed.2014.1319

[31] Drennan, V.M., Halter, M., Brearley, S., Carneiro, W., Gabe, J., Gage, H., et al. (2014) Investigating the Contribution of Physician Assistants to Primary Care in England: A Mixed-Methods Study. Health Services and Delivery Research, 2. https://doi.org/10.3310/hsdr02160

[32] WHO (2009) Dengue: Guidelines for Diagnosis, Treatment, Prevention and Control. World Health Organization, Geneva.

[33] Doblecki-Lewis, S., Chang, A., Jiddou-Yaldoo, R., Tomashek, K.M., Stanek, D., Anil, L., et al. (2016) Knowledge, Attitudes, and Practices of Florida Physicians Regarding Dengue before and after an Educational Intervention. BMC Medical Education, 16, 124. https://doi.org/10.1186/s12909-016-0647-8

[34] Al-Zurfi, B.M.N., Fuad, M.D.F., Abdelqader, M.A., Baobaid, M.F., Ghazi, H.F., Ibrahim, M.H., et al. (2015) Knowledge, Attitude and Practice of Dengue Fever and Health Education Programme among Students of Alam Shah Science School, Cheras, Malaysia. Malaysian Journal of Public Health Medicine, 15, 69-74.

[35] Lee, V.J., Chow, A., Zheng, X., Carrasco, L.R., Cook, A.R., Lye, D.C., et al. (2012) Simple Clinical and Laboratory Predictors of Chikungunya versus Dengue Infections in Adults. PLOS Neglected Tropical Diseases, 6, e1786. 
https://doi.org/10.1371/journal.pntd.0001786

[36] Pan American Health Organization and Espinal, M.A. (2017) World Health Organization Tool for the Diagnosis and Care of Patients with Suspected Arboviral Diseases.

[37] Toda, M., Zurovac, D., Njeru, I., Kareko, D., Mwau, M. and Morita, K. (2018) Health Worker Knowledge of Integrated Disease Surveillance and Response Standard Case Definitions: A Cross-Sectional Survey at Rural Health Facilities in Kenya. BMC Public Health, 18, 146. https://doi.org/10.1186/s12889-018-5028-2 


\section{Supplementary File}

Organisation de Coordination pour La lutte Contre les Endémies en Afrique Centrale P.O Box 15665, Yaoundé Cameroon Tel: + 23722232232

Fax: + 23722230061
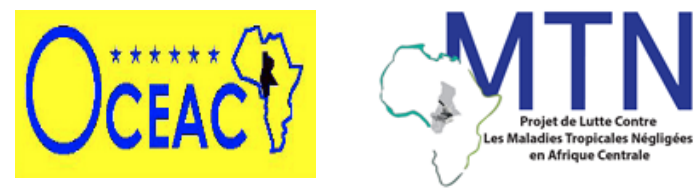

Web: http:// www.oceac.org

\section{Healthcare workers survey on Dengue and Chikungunya \\ Questionnaire}

\begin{tabular}{|c|c|c|}
\hline \multicolumn{3}{|c|}{ 0. IDENTIFICATION } \\
\hline 0.1 & Date & ${ }^{\prime} \_/ 2020$ \\
\hline 0.2 & Interviewer & \\
\hline 0.3 & Region & \\
\hline 0.4 & City & \\
\hline 0.5 & Health District & \\
\hline 0.6 & Respondent code & \\
\hline 0.7 & Sex & \\
\hline 0.8 & Profession & $\begin{array}{l}1 \text { = Medical assistant; } \\
2 \text { = Laboratory technician; } \\
3 \text { = Nurse; } \\
4 \text { = Medical doctor; } \\
5=\text { others }\end{array}$ \\
\hline \multicolumn{3}{|c|}{ 1. GENERAL KNOWLEDGE REGARDING DENGUE AND CHIKUNGUNYA } \\
\hline 1.1 & Did you ever heard of Dengue and Chikungunya? & $\begin{array}{l}1=\text { Yes } \\
2=\text { No } \\
\text { If yes, how? }\end{array}$ \\
\hline 1.2 & What are their causative pathogens? & \\
\hline 1.3 & How are both diseases transmitted to humans? & \\
\hline 1.4 & Cite some symptoms of both diseases? & \\
\hline 1.5 & What is the most affected population group? & \\
\hline \multicolumn{3}{|c|}{ 2. MANAGEMENT OF DENGUE AND CHIKUNGUNYA CASES } \\
\hline 2.1 & How can both diseases be diagnosed? & \\
\hline 2.2 & $\begin{array}{l}\text { What are the preventive measures against dengue and } \\
\text { chikungunya? }\end{array}$ & \\
\hline 2.3 & How are managed dengue and chikungunya cases? & \\
\hline 2.4 & $\begin{array}{l}\text { Do you think that Cameroonian health personnel is well } \\
\text { trained to manage dengue and chikungunya cases? }\end{array}$ & \\
\hline 2.5 & $\begin{array}{l}\text { How can dengue and chikungunya cases management can } \\
\text { be improve? }\end{array}$ & \\
\hline
\end{tabular}

